\title{
El concepto de literatura en los manuales de enseñanza
}

\author{
FRANCISCO GONZÁLEZ GAXIOLA*
}

Resumen:

En este ensayo se presentan los resultados del análisis de cuatro manuales de enseñanza de la literatura a nivel bachillerato. A partir de los resultados se infieren algunas observaciones sobre teoría literaria, acercamientos metodológicos para la didáctica de la literatura, conceptos de teoría y crítica literarias y la manera como todos ellos influyen en las creencias de los profesores y las prácticas en el aula. El objetivo general que da sentido a estas observaciones consiste en escudriñar cómo se manifiesta la teoría y la crítica literarias en los manuales de enseñanza de la literatura. La metodología seguida consiste en la descripción de los manuales con base a cuestionarios convertidos en cuadrículas, en donde se registran los datos elicitados, base para las reflexiones y comentarios sobre la problemática de su enseñanza

Palabras clave:

Didáctica de la literatura, teorías literarias aplicadas, manuales de enseñanza, comprensión e interpretación.

Existen muchas disquisiciones sobre lo que es y no es literatura. La definición de este concepto o la circunscripción de ella a un campo de estudio o de trabajo son un supuesto prioritario en la teoría y la

\footnotetext{
* Profesor-investigador. Universidad de Sonora.
} 
crítica literarias. Sin embargo, las políticas educativas y los proyectos curriculares parecen, al conservarlo en su ambigüedad, evitar estratégicamente la precisión de este término. Cuando se intenta reflexionar sobre este concepto poca o ninguna trascendencia ha tenido lo que en la escuela los alumnos y los profesores piensan de ella o lo que hacen con ella. Pocos se detienen a establecer una relación entre el uso concreto o manejo instrumental, el que se hace en la escuela, con el implicado en los manuales de enseñanza y, en el nivel más abstracto, con el teórico-conceptual. Cada uno de estos tópicos en sí y la relación entre sí constituyen un objeto de estudio digno de atención y trascendente tanto para la teoría misma como para la didáctica de la literatura. ${ }^{1}$

En el análisis que presentamos a continuación nos limitamos a exponer el procedimiento seguido en virtud de una idea matriz y generadora de la investigación: teorías literarias aplicadas, y un objetivo subsecuente: tomar como objeto de estudio la enseñanza de la literatura, para fortalecerla con creatividad y sistematización. ${ }^{2}$

1 "La enseñanza de la literatura en el bachillerato a través de los textos" es un avance de investigación inscrito en un proyecto mayor Teoría literaria y Didáctica de la lengua y la literatura. Este avance particular está dedicado al análisis de los manuales de enseñanza de la literatura (universal y castellana) a nivel bachillerato, en España. Los siguientes avances harán lo respectivo con los manuales de enseñanza en los Estados Unidos de América, en Argentina y en México. La parte concreta y de aplicación corresponde a la indagación sobre datos de enseñanza a partir de lo que declaran los manuales de enseñanza de la literatura en sus diversos apartados, como presentación, exposición, objetivos y actividades. El proyecto de investigación del que forman parte estos avances, consta de cuatro partes a) un análisis bibliográfico con enfoque didáctico de las diversas teoría literarias y sus acercamientos metodológicos, es decir, un rastreo sobre aportaciones de la teoría a la didáctica de la literatura a la manera como lo plantean Bordons, Colomer, Ballester, Mendoza, entre otros, b) los datos y observaciones recogidos de los manuales, c) las creencias y saberes de docentes y dicentes elicitados mediante entrevistas y cuestionarios y, finalmente, d) habre-mos de comparar datos obtenidos de tres fuentes distintas -teorías, manuales de enseñanza y declaraciones de académicos y estudiantes- para terminar haciendo una propuesta con diversas consideraciones para la enseñanza de la literatura.

${ }^{2}$ Un paso inicial de esta investigación consistió en la elaboración de una cuadrícula base que sirviera de instrumento para vaciar información recogida de la descripción de los manuales. Un enlistado de puntos fundamentales de descripción de la Doctora Glòria Bordons (Universidad de Barcelona, 2003), sirvió de 
1. Literatura Universal. David Fernández. Barcelona: Castellnou Edicions, 1999.

2. Literatura Castellana. José Quiñonero. Barcelona: Ediciones Octaedro, 1998; primera reimpresión 2001.

3. Literatura Universal. Ferrán Gadea y Andreu Freixes. Barcelona: Editorial Teide S.A., 2002.

4. Literatura Española 2. Fernando Lázaro Carreter y Vicente Tusón. Madrid: Grupo Anaya, 1995.

1. Preferencia de corriente de estudio de la obra literaria.

La intención inicial de nuestro proyecto se dirigirá a identificar declaraciones explícitas sobre corrientes de teoría literaria que hicieran los autores de manuales en sus presentaciones. De no resultar productiva la búsqueda, se pasará a rastrear en las presentaciones y desarrollo de sus exposiciones la preferencia teórica, manifestada ya no tan explícitamente. Culler objeta la pretensión de que las teorías literarias tengan por objetivo proporcionar metodologías o acercamientos hermenéuticos para el estudio de las obras literarias. La teoría literaria, según él, tiene preocupaciones abstractas, de mayor ambición, y otros puntos de interés como para detenerse en puntos tan concretos que le pertenecen a la crítica literaria, como esfera de aplicación. Sin embargo, podrá considerarse que casi todas las metodologías de análisis literario derivan más o menos directamente de una disciplina del conocimiento o de una corriente de teoría literaria. Para el primer caso tenemos, la psicología (de orientación psicoanalítica), la sociología (en gran medida de enfoque marxista), la antropología (preferentemente de orientación mítica). Para el segundo caso existen además otras aproximaciones que no propiamente se basan en un cuerpo teórico previo, como lo son el comentario y análisis de texto, o prácticas provenientes, por ejemplo, del neo criticismo norteamericano o del

base para la captura de datos. Dichos puntos se aplicaron por primera vez al texto de David Fernández, y la evaluación del funcionamiento de dicha herramienta sirvió para identificar los puntos que no resultaban adecuados; también sirvió para modificar la presentación de los items imprecisos, y finalmente para evaluar los registros que se daban como respuesta a cada uno de los items identificados. 
criticismo moral inglés. Por otro lado hay que aceptar también que los presentadores de manuales, lo quieran o no, consciente o inconscientemente, con o sin conocimiento de causa, aplican propuestas de análisis más o menos sistemáticas. Contrariamente a lo que opina Culler, pues, hay varios teóricos de la didáctica de la literatura (entre otros, Glòria Bordons, Mendoza Fillola, García Garrido, Colomer, Meix Izquierdo, Ana Reyes, Daniela Bertochi) que son más optimistas sobre las aportaciones que puede ofrecer la teoría literaria. En conclusión, se espera que del análisis de las teorías, de las creencias de los profesores y del estudio de lo que subyace a las prácticas académicas, usadas y aconsejadas en los mencionados manuales, se puedan inferir conclusiones interesantes y prometedoras.

Se esperaría que la presentación que hacen los autores de manuales hiciera explícita alguna declaración sobre aspectos que relacionaran la teoría literaria con su aplicación práctica en la enseñanza; o también, en general, se esperaría que a lo largo del texto hicieran consideraciones sobre las temáticas propiamente teóricas mediante interrogaciones, dudas, inquirimiento de funciones de la literatura y por lo menos alguna advertencia sobre cuestionamientos a veces inevitables en el tratamiento del fenómeno literario: naturaleza de la narrativa, naturaleza de los géneros, limitaciones de la historia literaria, entre otros. De no ser así, y quizá además de lo anterior, se esperaría que se pudiera inferir del tratamiento a determinados puntos la inclinación por alguna corriente de teoría literaria o de acercamiento metodológico de análisis de las obras literarias.

Ninguno de los autores de los manuales por nosotros estudiado declara en la presentación del texto (donde podría esperarse que apareciera alguna indicación al respecto), ni en los objetivos ni en la presentación histórica o comentada de los textos, cuál orientación metodológica es de su preferencia para el mejor estudio y recepción de la literatura entre los estudiantes del bachillerato. Los autores del cuarto libro de texto, Fernando Lázaro y Vicente Tusón, son, al parecer, los únicos que aparte de una presentación general del manual, hacen una somera introducción de la teoría literaria, su campo de estudio y la ubicación de la disciplina, respecto a lo que se intenta con el estudio de la literatura al nivel bachillerato. Pero, a pesar 
del acierto por intentar ubicar los estudios literarios y su relación con los objetivos del texto, el tratamiento de Lázaro y Tusón parece quedar desligado del desarrollo temático e histórico subsiguiente porque no se retoma ni se la aprovecha para incluir cuestiones propias de la teoría literaria, como las ya mencionadas arriba. No se vuelve a mencionar esta primera parte introductoria ni se intenta relacionarla con contenidos tratados ni, con base en ella, se pasa a cuestionar o problematizar géneros, disciplinas de estudios, conceptos retóricos, el papel del lector, historia de la literatura, entre otros posibles asuntos. La información que sobre aspectos teóricos se puede obtener es relativamente escasa, aunque se pueden inferir líneas de tratamiento a conceptos o términos literarios, principalmente, como lo exponemos adelante.

Los autores de texto, sin embargo, unánimemente se decantan en la práctica (pero sin reflexionar sobre ella ni mencionar otras posibles alternativas) hacia la misma aproximación metodológica. Todos ellos optan por realizar el estudio de las obras mediante el comentario de textos o variantes metodológicas similares, con un seguimiento progresivo histórico y con diversos grados de intromisión en los fenómenos concomitantes a la vida del autor y a la producción de la obra

La teoría más cercana al uso diario, la exponen varios de los autores en la presentación de conceptos aledaños al análisis de los fragmentos o selección de obras. Empezando con los más urgentes, como son los géneros literarios, pero insistiendo además en algunas ideas imprecisas que se tienen sobre la narrativa o la poesía lírica, digamos: autor, narrador, alter ego, narratario, personaje, actante, etc. Así pues, formar a un lector supone dotarle de instrumentos de análisis. De ahí la conveniencia de partir de conceptos fundamentales como género literario, tema, tópico, mito, símbolo, sobre todo para facilitar la conexión de la literatura castellana con las otras literaturas nacionales y con la literatura universal. Las actividades de comparación entre varias obras de distintas culturas y lenguas capacita al alumno a ver por un lado lo sui géneris de su literatura nacional. Los mencionados a continuación son, según Segre, elementos que integran un material antropológico común. Son motivos universales o al menos comunes para la literatura occidental, pues pasan de unas literaturas a otras, luego se incrus- 
tan en los soportes audiovisuales y terminan en la cultura de masas. Tales son: el amor, la muerte, la lucha entre el bien y el mal, la mujer ultrajada, el justiciero vengador de afrentas, etc. (cf. Ana Oroz$\mathrm{co})$.

Se podría esperar que cada uno de los textos tuviera una presentación, sin embargo, no es el caso. La Literatura Castellana de José Quiñonero carece de ella, lo cual hace correr el riesgo de conducir al profesor que utiliza el texto como guía y a los mismos estudiantes, a trabajar sin orientación, sin prioridades. Toda actividad, ejercicio, tarea cobra sentido teniendo de fondo un objetivo pero, en general, en los manuales mencionados se otorga poca importancia a la explicitación de los objetivos finales. En especial, sólo un texto (Fernández) se detiene a enunciar los objetivos de aprendizaje para cada unidad; los demás textos se conforman con hacer una alusión a los objetivos generales en la(s) página(s) de "Presentación" del texto. Para los otros manuales explicitar los objetivos finales pareciera hacerse descansar en las mismas actividades de aula y, por lo tanto, pasan a ser inferidos

La cantidad de información que debe proporcionar un texto siempre será problemática, sobre todo para quienes siguen un procedimiento de enseñanza basado en un análisis textual comentado con un fondo de historia. ¿Qué tanta información debe proporcionarse para que se considere que satisface en lo mínimo el cumplimiento del objetivo? Ubicación histórica del autor, identificación de la obra, información de la época, la sociedad, la política, los principales eventos históricos, culturales. De acuerdo, pero ¿qué tanto es suficiente? ¿Qué tanta información es necesaria? Aquí cabrían comentarios críticos de los autores sobre el cuestionamiento de la aproximación y de por qué y qué tanta información poner al alcance del estudiante y cuál y cuánta información pedirles que busquen por ellos mismos en enciclopedias o en historias de la literatura o en textos de historia general o en la red. Es un punto difícil de dirimir sobre todo cuando los textos carecen de objetivos explícitos generales, aunque los objetivos de unidad pueden paliar un poco esta responsabilidad.

En cuanto a cantidad de información, sólo el texto de David Fernández carece de un trasfondo histórico sin justificar la causa para dicha ausencia. Quizá la razón se ubique en el principio del 
nuevo criticismo y/o corrientes de análisis formalistas o inmanentistas, que conscientemente obvian la información histórica para enfrentar al estudiante directa y únicamente a la lectura y comprensión del texto. El hecho de que en dicho manual se incluyan cuestionarios para cuatro obras con seguimiento pormenorizado de ellas pero sin contextualización sociológica o histórica, refuerza dicho punto. A colación sale el hecho positivo de ser el único de los cuatro manuales en reforzar la lectura completa de obras mediante un seguimiento de ellas y no satisfacerse con fragmentos, citas o selección de dramas, poemas, novelas, etc.

\section{Presencia de los textos literarios}

¿A qué textos debe el profesor de literatura enfrentar a sus estudiantes? ¿Cuáles y cuántas son las obras mayores, de la tradición literaria o no, cuya enseñanza garantizaría el cumplimiento de objetivos y competencias, cualesquiera que sean éstas, en la formación de los educandos? La respuesta que se busca responde en síntesis a la pregunta qué enseñar, si es que las obras literarias se pueden enseñar. Antes de abordar el canon literario escolar, es pertinente hacer un señalamiento sobre la extensión de los textos con que se trabaja en los manuales. Todos los textos que en los presentes manuales aparecen son muestras, fragmentos, selecciones. No se trabajan los textos completos. Hay que reconocer, sin embargo, que el recurso obligado y en cierta medida práctico a las antologías, constituye un instrumento útil para la lectura intensiva que apunta a la adquisición específica de capacidades. Pero no hay que olvidar la importancia del sentimiento de plenitud que se deriva de la lectura de un texto completo y de su coherencia interna. Para ello se puede recomendar en poesía no aceptar un poema solamente para ilustrar una corriente, ni tampoco utilizar un fragmento para aclarar una situación por ilustrativa o cómica que pueda resultar. ¿Por qué no ver, al menos, todo un acto de una tragedia, o un capítulo de una novela, de tal manera que no se caiga en reducción extrema o en la selección demasiado arbitraria de los retazos? (Bertochi)

En tres de los manuales, los textos seleccionados pertenecen todos al canon tradicional. Carreter y Tusón hacen una rara inclusión para la literatura española. En él se menciona, presenta, inclu- 
so se ofrece una muestra de la producción de Santa Teresa de Jesús, Libro de su vida, pero se olvida a la santa cuando se pasa al apartado de actividades o lecturas por analizar. Aunque aislado, este hecho, que pareciera concesión al feminismo, convierte al manual en el más incluyente, en este respecto. En cuanto a inclusión geográfica, este mismo manual de literatura española decide anexar un apartado para literaturas hispanoamericanas del siglo XX (unidad 18), pero es significativa la ausencia de obras literarias de siglos anteriores, lo mismo que de otras latitudes como Filipinas, Puerto Rico y las Antillas. Por fin, el mismo manual, en la última unidad "Otras literaturas" (unidad 19), incluye, sin detenerse a analizarlas, otras literaturas no propiamente 'españolas', la literatura gallega, la catalana y la del País Vasco. Sin embargo, hay ausencia total de muestras de literaturas de temática periférica, digamos, literatura juvenil, policíaca, ciencia ficción, novela rosa.

Los criterios para la selección de obras, el canon literario escolar, se reducen a patrones seguros y tradicionales, pero no cuestionan ni siquiera desde un punto de vista didáctico la ausencia de las llamadas otras literaturas, las que precisamente son consumidas con fruición por los estudiantes fuera del salón de clase. Aparte de las ya mencionadas en el parágrafo anterior y conocidas como literatura de la periferia (siguiendo la terminología de Even-Zohar, cit. en Iglesias Santos), las 'otras literaturas' constituyen una diversidad de prácticas culturales que cuestionan nuestra enseñanza de siglo XXI. Además amagan con relegar definitivamente la literatura tradicional y sustituirla por otra de verdadero atractivo e interés para los jóvenes, práctica que terminará posiblemente con borrar la frontera entre cultura sancionada por la ideología dominante por un lado y, por otro, la cultura popular o juvenil o contracultura, etc. Representantes de estas prácticas son muchas, pero quizá la más importante por su vigencia y predominio actual, sea la denominada psicoliteratura (literatura para adolescentes que presenta problemas urgentes de atender y que a los estudiantes la literatura de escuela no les dice nada al respecto). Muestras de literatura con esas características son las historietas, las letras de canciones, los graffiti, los videoclips, etc.

Por otro lado, disentimos de la posición de Daniela Bertochi al referirse al hecho de que el usar indiscriminadamente textos litera- 
rios y no literarios en las antologías escolares, confunde la especificidad de la literatura, y se le usa en consecuencia únicamente para un estudio de orientación temática o de tipología textual. Para los escolares de nivel secundaria o bachillerato, es preferible utilizar todas las estrategias que conlleven al desarrollo de la competencia literaria aún con el riesgo de incurrir en ese peligro o limitación o indebido uso mencionado por Bertochi. El criterio por ella defendido parece ser inoperante, si no desfasado. Las fronteras del discurso literario actual implican la ampliación de los límites de la llamada 'verdadera' literatura, ya que se ha vuelto borrosa la frontera entre lo que es literario propiamente dicho y lo literario dentro de lo no literario, es decir, lo que desde una perspectiva pragmática tienen el cine, la pintura, la televisión y otras implícitas en las nuevas tecnologías.

En lo general, en los manuales analizados hay ausencia notable de obras que se encuentran en la frontera de géneros, géneros mixtos o muy cercanos a la 'literatura propiamente dicha'; no se han admitido muestras de guiones cinematográficos o de telenovela, radio, lírica popular o canciones. Curiosamente, un solo manual (Lázaro Carreter y Tusón) incluye muestras que la historia de la literatura recoge del folklore de la Edad Media o de los tiempos de la Reconquista, composiciones anónimas que solían usarse para acompañar la actividad laboral. La pregunta permanece sin responder, ¿por qué de la Edad Media, sí, y de la de hoy, no?

El texto de F. Gadea y A. Freixes es, en este último aspecto, el manual más abarcador en aplicaciones. Considera en sus actividades de registro o de creación, la composición de guiones y ensayos alejados de la temática literaria stricto sensu. Desafortunadamente dichos géneros no son analizados en la parte expositiva central. De ello se puede concluir que para los autores tales obras siguen teniendo un carácter periférico sin duda, y sólo se les reconoce su estatus para formar parte de la problemática que, sin embargo, es re-enviada a los alumnos para que, fuera de clase y después, la discutan entre ellos.

No es de sorprender la ausencia casi total de escritoras mujeres. Apenas dos sobre 72 escritores cita la Literatura Universal de David Fernández, la de F. Gadea y A. Freixes cita menos de cinco pero no se lleva a actividades el material de ninguna; y en los manuales 
de Literatura Castellana de Quiñonero o Española de Lázaro, no se trabaja la producción literaria de ninguna, con la casi excepción también de Santa Teresa, ya mencionada..

En lo que atañe a los géneros, el recuento de los textos (todos ellos selecciones o fragmentos) muestra un total predominio de la poesía (lírica, religiosa, satírica, etc.) La narrativa aparece en segundo lugar, quizá porque generalmente los fragmentos de este género suelen ser mayores; aún así, nunca se llega a incluir un capítulo completo de una novela o un acto de un drama o tragedia. Como excepción aparece la reproducción de un artículo periodístico, mezcla de ensayo y narración, de Mariano José de Larra, en el manual de F. Gadea y A. Freixes. Casualmente, el mismo artículo es reproducido por F. Lázaro, pero reducido a la línea argumental y esencial, y da la impresión de que se le incluye sólo por la representación divertida de una anécdota satírica, cuando lo importante, creemos nosotros, no sería la extensión del material, sino precisamente el de la cualidad de lo completo y el de coherencia interna.

\section{El manejo de la interpretación}

Un tema peliagudo es cuestionarnos la diferencia entre comprensión e interpretación. En el nivel que aquí se estudia no existe ningún manual de enseñanza que aborde dicha temática, quizá por prudencia, buen sentido o simple concepto de pertinencia de parte los autores de los manuales. Lo que está detrás de la letra es muy difícil de enseñar y de aprender incluso para un adulto. Temas como el doble sentido, la ironía, la alegoría, o simplemente el significado detrás del significado no prometen resultados claros en los niveles de enseñanza media, al parecer. De momento no ahondamos en el análisis de este tema y sólo referiremos lo que en los manuales mencionados se trata al respecto, el cual, sin embargo, permea varios apartados: actividades, competencias, objetivos.

Por lo que se desprende de las actividades de aprendizaje, generalmente la clase de literatura está dedicada a ejercicios individuales, en los que el alumno ha de realizar alguna tarea casi siempre solo. Los textos de F. Gadea y A. Freixes, y de F. Lázaro y V. Tusón en cambio invitan a la confrontación de resultados de una actividad y en consecuencia las actividades de discusión en clase re- 
sultan muy importantes. Así sucede con el tratamiento que se da, por ejemplo, a la interpretación, sin ser ésta considerada como la visión aceptable y correcta que el instructor ha de enseñar. Sin embargo, el concepto de interpretación propuesto en los manuales no va más allá de la sola comprensión del contenido y tampoco se arriesga a poner en contacto al alumno con la intencionalidad del autor. No se hace pero, de hacerse, podría el alumno comprender la relatividad de cualquier autoridad respecto al imperio o dominio de quien quisiera obligar una interpretación, incluso la del maestro, y cómo, por lo tanto, la del estudiante mismo es respetable, por equivocada que pueda parecer a primera vista. Además, en estas últimas actividades no queda claro dónde queda o qué papel desempeña el instructor o profesor de literatura, si dirige la asamblea, si se oculta, o si interviene al final para sancionar qué es lo que se debe concluir, etc. Es evidente que promover la comunicación literaria mediante grupos de estudio que negocien los significados y las interpretaciones en el aula sirve para ver en qué grado se involucra la participación de los lectores.

La interpretación o ejercicios hermenéuticos de las obras no son enfatizados ni enviados aparte; es presumible que se proceda así para hacer tomar conciencia a los alumnos de que en la interpretación juega un papel preponderante lo que el estudiante entiende de la lectura (cf. Holland, Bleich, Fish). Los manuales tratan este apartado de una manera global, excepto el de Gadea y Freixes. Todos los manuales se cuidan bien de no desatender el procedimiento de las preguntas sobre el fragmento de lectura, dando a entender así que las preguntas están construidas como manera de llamar la atención sobre los aspectos dignos de ser observados, comentados, interpretados y evaluados. Falta aclarar si la respuesta a las preguntas dudosas o difíciles por la ambigüedad del texto serán trabajadas como enseñanza por parte del instructor o por negociación entre partes: entre los estudiantes mismos o entre estudiantes y profesor. En este punto, ninguno de los manuales precisa el grado de participación del profesor (cf. César Coll).

Desde el punto amplio de interpretación se pueden considerar también en este apartado las respuestas de los alumnos, entendidas como conductas observables, no solamente la verbalización oral o escrita sobre una obra. Tales serían los casos concretos para activi- 
dades de carácter lúdico, jugar a partir del texto a través de actividades como subrayar el texto (no subrayar como sinónimo de enfatizar, muy frecuente en Lázaro y Tusón), o transferir un texto de literatura a pintura o convertir un género en otro (de tratado serio a sátira o viceversa, por ejemplo), ampliar el texto con innovaciones al final, cuestionar el texto en clase (Para ejercicios muy interesantes en el ámbito de la literatura comparada véase Bordons, Díaz-Plaja). Con todas estas actividades, el manual de Gadea y Freixes sobresale respecto a los otros. Su texto también es el único en este sentido en trascender la literatura para auxiliarse de otras artes y fortalecer en consecuencia el conocimiento y la formación literarios.

La invitación a volver de la clase de literatura un lugar para la lectura y la discusión del contenido, es también una oportunidad para que aparte de la recepción, los estudiantes den rienda suelta a sus creaciones literarias orales y escritas, en las que también pueden intervenir recursos audiovisuales y de artes aledañas. Tales actividades sólo en Quiñonero son abundantes y menos abundantes en Gadea y Freixes. Igualmente en este sentido el texto de Quiñonero se aleja considerablemente de los otros por la atención, en grado muy considerable, dirigida a la escritura de creación. Cada unidad de su manual tiene un apartado especialmente dedicado a sacar a los alumnos de la conformista recepción de la literatura y a invitarlos a producir y crear literatura por su propia cuenta. Se invita a los estudiantes a crear relatos, guiones y productos similares, incluso la dramatización tiene lugar en este manual, aunque de forma no muy decidida.

\section{Competencias y sub-competencias}

El apartado seis de este ensayo está dedicado al análisis específico de actividades, pero aquí se busca reflexionar sobre los términos que conocemos como competencias y que implican por lo tanto actividades. A partir de esta consideración se pueden desprender muchas cosas. La más importante es una que tiene que ver directamente con la concepción de literatura que tienen los autores de los manuales por un lado, y por otro, las creencias y saberes que los profesores tienen en el cumplimiento de competencias y sus 
diversos niveles (ver Cantero y Mendoza) logradas éstas, por supuesto, a través de actividades. Los autores de los manuales pueden influir directamente, y sin duda lo hacen, dirigiendo a maestros y alumnos a desarrollar competencias específicas evitando o disminuyendo en consecuencia la importancia de otras. El señalamiento de actividades en los textos favorece el cumplimiento en la adquisición de competencias. Dependiendo de la disposición de los alumnos ante la materia, los profesores se circunscribirán a los ejercicios mencionados en el manual o los utilizarán sólo de apoyo para modificaciones o tratarán de ir más allá aportando nuevas ideas.

Este apartado está dirigido a elicitar qué se busca con la enseñanza de la literatura, qué competencias se intenta que los estudiantes desarrollen. En él se apuntan básicamente competencias de comprensión y de comunicación oral y escrita, lectora y auditiva, seguida del recurso a otros objetivos, como las de adquisición del gusto literario o artístico y el desarrollo del espíritu crítico, entre otros.

Como es conocido de todos, la enseñanza de la literatura ha retrocedido en las currículas de la mayoría de los sistemas educativos en Occidente, y se dedica, en consecuencia, cada vez menos espacio y tiempo a la literatura y al arte en general. Así puede constatarlo un seguimiento de las reformas a los ordenamientos de la enseñanza y las modificaciones a los planes de estudio de las escuelas pertenecientes al nivel de enseñanza secundaria, de bachillerato y de nivel superior (Lázaro Carrreter, B. D. Coto, Garrido, entre varios) En casi todo occidente, los embates sufridos por los departamentos de humanidades, y en particular de literatura, ocurren cada vez que las luchas por la distribución del presupuesto hace patente la necesidad de sacrificar cursos, conferencias, proyectos de investigación y espacios en estos ámbitos en general (Culler, Graff, Garrido). Es importante entonces analizar y reflexionar sobre las competencias que la lectura de la literatura habrá de desarrollar en los lectores de la escuela.

Las competencias que tradicionalmente se le ha reconocido a la enseñanza de la literatura en ámbito escolar se desarrollan en cuatro niveles: 
a) en el nivel estético, despertar el gusto por la literatura; la búsqueda del desarrollo del gusto es compartida con las asignaturas artísticas;

b) en el nivel lingüístico, tomar conciencia del lenguaje y, por lo tanto, desarrollar la capacidad de comunicación oral y escrita;

c) en el nivel cognitivo, la capacidad para reconocer que la literatura es una forma de comprender el mundo;

d) y en el nivel ético, la adquisición de actitudes y valores.

¿Puede seguir siendo convincente y suficiente para su defensa, declarar que la literatura en la escuela sirve para desarrollar la formación estética del estudiante? Las evaluaciones que hacen los organismos institucionales y legislativos, basados en criterios cada vez más prácticos y utilitaristas, obliga a los convencidos de las ventajas que tiene la enseñanza de la literatura a buscar funciones que sean más atractivas y aceptables para los organismos e instituciones rectores de la educación. Aunque pueden llegar a convencer una segunda y tercera funciones declaradamente prácticas, la literatura corre el riesgo de perder su identidad para servir solamente como medio o instrumento para que los estudiantes adquieran habilidades de comunicación y de expresión.

¿Qué tanto comprende un texto el estudiante? No digamos únicamente un texto de carácter expositivo, de lenguaje científico o de divulgación, en cuyos casos se realizan reactivos de examen de varios tipos (de opción múltiple, de rellenado, de respuesta general, de respuesta específica, de re-configuración, de seguimiento lógico, entre otros) para medir su capacidad de comprensión. Todas las opciones apuntadas anteriormente tienen la ventaja de aportar resultados cuantitativamente mensurables y por lo tanto, ofrecen la oportunidad de inferir a partir de ellos, conclusiones convincentes. Herramientas y resultados como los mencionados aparecen en investigaciones que se inscriben en el método científico y su parafernalia experimental, vigente y aplaudida sobre todo en los Estados Unidos de América. En los últimos años, sin embargo, la investigación cualitativa y etnográfica parecen tener una creciente aceptación en los proyectos de investigación didáctica. 
En el caso de literatura, la obtención de datos cuantificables provenientes de la interpretación o de la comprensión de las lecturas, suele resultar difícil debido a la inestabilidad y ambigüedad naturales en la literatura, en versos, en oraciones, párrafos e incluso en el significado de toda la obra. A como se entiende la interpretación en el ámbito escolar normal, generalmente no va ésta más allá de la pura comprensión del contenido, y no se ofrece oportunidad para ver la operación comunicativa a través de un primer acercamiento o 'contacto' con la intención del autor (cf. Bertochi). El procedimiento tradicional para tener acceso a la interpretación del alumno usa estrategias de manejo complicado en el tratamiento de la comprensión. Las estrategias de recurso común son: la paráfrasis, el resumen, el conocimiento del léxico, la recreación de ambientes, historias y personajes, entre otros. Respecto al primer procedimiento, la paráfrasis, solamente el texto de Gadea y Freixes lo utiliza para tal efecto, pero en general en los diversos manuales, el léxico es trabajado de una manera variable: algunos enfatizan el aspecto del significado a nivel palabra con actividades que piden que seleccionen y construyan campos semánticos; otros solicitan la búsqueda de vocabulario en el diccionario o en la enciclopedia (para lugares, nombres de héroes o dioses, personajes, obras literarias, pinturas, compositores). El texto de Fernández se centra en la mitología, pero después parece olvidarse de la actividad léxica o de construcción de vocabulario. El énfasis es mayor en L. Carreter y muy rica y variada en el manual de Gadea y Freixes.

La caracterización de los personajes es un ejercicio muy rico en implicaciones de construcción de significado, porque no todo lo que se menciona de algún personaje es explícito sino que mucho es imaginado y además mucho también es inferido. La caracterización se obtiene de analizar lo que un personaje hace o piensa, y no sólo mediante calificativos sintéticos referidos por el narrador o por otros personajes. El recurso de la caracterización está presente en tres de los manuales, excepto en el de Gadea y Freixes.

Ejercicios dirigidos a ambientar el contenido de las lecturas con el ánimo de motivar a los estudiantes y hacerles comprender el sentido de leer un texto que, de otra manera, parecería fuera de lugar, son usados con frecuencia en textos que hacen una presentación temática de sus lecturas. Sólo por poner un ejemplo: antes 
de abordar el tema de la arbitrariedad del estado en Antígona de Sófocles o en El proceso de Kafka, un manual puede abordar la temática introduciendo aquellos casos inmediatos y cercanos, que los estudiantes puedan comprender mejor y, por lo tanto, a interpretar, criticar, evaluar. Sin embargo, de los manuales aquí referidos, que hacen un seguimiento histórico y casi causal de la literatura, dicho acercamiento no aparece sino en un solo texto, el de Gadea y Freixes. En él se acude sistemáticamente al tratamiento de interesantes temáticas a través de fragmentos de ensayos de reconocidas autoridades en la crítica literaria.

Ejercicios más elevados y comprometidos con la apropiación de la interpretación de los significados y sentidos de las lecturas son aquellos tendientes a explicitar y por lo tanto fundamentar el gusto o preferencia personal, reconociendo aciertos, limitaciones, carencias e incluso partes mal logradas. Los manuales de Quiñonero y de Gadea y Freixes recurren a ellos con frecuencia.

\section{Acercamiento metodológico}

Si se enfatiza la actividad de fundamentar el gusto personal en cada unidad, entonces se puede concluir que los autores tienen en mente otorgar papel preponderante al lector no sólo en la construcción del significado y su interpretación sino también en la de valoración y evaluación que le merecen las lecturas. A partir de las lecturas los alumnos formulan juicios sobre el mérito del texto, pero también construyen juicios de valor sobre situaciones descritas al interior de la obra.

Los cuatro manuales consideran importante fortalecer la expresión escrita, aunque sea sólo para la redacción de resúmenes. Sin embargo, la expresión escrita puede salirse de los márgenes conservadores pero mínimos de la redacción racional, y pedir a los alumnos que creen o recreen, mediante las variantes ya comentadas, los textos estudiados. De momento, aquí recordamos las más socorridas y posiblemente más productivas: escribir cuentos, narraciones en general, diálogos, guiones, cartas a personajes, modificaciones de finales de cuentos o historias. El texto de Quiñonero se detiene muy especialmente en esta actividad para la cual en cada unidad dedica un apartado de cuatro o cinco ejercicios de creación 
dirigidos tanto a la expresión escrita como a la expresión oral. Por su parte, el manual de Gadea es rico por la variedad de las actividades a que recurre, las cuales se dirigen a la adquisición de una amplia competencia literaria mediante actividades de comparación o relación con otras disciplinas y artes como la pintura y la música, arquitectura, la historia. Entonces las pequeñas composiciones escritas, a veces se convierten en reflexiones de comparación de la literatura con diversos medios (cine, pintura, música, ópera, telenovelas). Este punto, muy importante, da muestra de una concepción de literatura muy especial, por su riqueza y amplitud de criterio para abordar las relaciones desde un punto pedagógico más amplio. Tal concepción de la literatura coincide con la de teóricos (Mukarovski, Jakobson) que consideran que la literatura forma parte de un sistema mayor, el artístico, y éste a su vez de otro más incluyente, la cultura (cf. Schmidt, Even-Zohar, Iglesias Santos).

Expuestos como ejercicios explícitos en el aula de clase, los dirigidos a la expresión oral son complemento o variante de los escritos. Desarrollar la competencia comunicativa, no sólo depende de lo que comprenda el estudiante sino también de lo que escriba y de lo que exprese oralmente. Tres de los manuales (excepto el de David Fernández) consideran con claridad las actividades de comprensión, lo mismo que las actividades escritas, y por lo tanto no las creen implícitas ni las toman por dadas o automáticas en la declaración de los ejercicios a través de verbos específicos como: leer, comentar, exponer, y similares.

Finalmente, lo más curioso respecto a los registros de niveles de recepción, es que tres manuales han olvidado el aspecto receptivo auditivo (no el oral de producción), no lo trabajan ni lo mencionan. Solamente el manual de F. Gadea y A. Freixes trabajan tal aspecto productiva y constantemente en varias actividades. Manejan el aspecto auditivo de comprensión, no sólo de historias o canciones, sino también a través de otros medios como la música y la ópera y el cine.

\section{Análisis de las actividades}

En nuestro caso presente el análisis de actividades ha resultado, aparte de interesante, un apartado muy productivo dadas las conclusiones 
que se pueden desprender del mismo. La conclusión más importante es una que tiene que ver directamente con la concepción de literatura que tienen los autores de los manuales por un lado y, por otro, las creencias y saberes de los profesores, quienes muy probablemente se intenta orientar. Los autores de los manuales pueden influir directamente, y sin duda lo hacen, dirigiendo a maestros y alumnos en la asignación de actividades específicas. El paradigma potencial de actividades favorece el cumplimiento de su labor a los docentes. Los profesores en el aula, dependiendo de la disposición de los alumnos ante la materia (entre otros factores), se circunscriben a los ejercicios mencionados en el manual o los utilizan sólo de apoyo para modificaciones o tratan de ir más allá aportando nuevas ideas, pero de una $\mathrm{u}$ otra manera suelen utilizarlos de base o referencia.

Dentro de la gama posible de actividades, una que resulta muy importante por sus consecuencias es la comparación de textos literarios en el ámbito de la literatura universal, de la literatura comparada y de la intertextualidad, pues ello capacita al alumno para ver, por un lado, lo sui generis de su literatura nacional y, por otro, la relación entre los productos culturales de otras lenguas y culturas lejanas o cercanas geográfica o históricamente.

Es curioso observar cómo los cuatro manuales se concentran en ciertas actividades en detrimento de otras. En un concentrado (mostrado a continuación) se presentan las actividades y las frecuencias registradas por los manuales con el ánimo de exponer un resumen de los datos de cuadrículas completas. Del concentrado de datos se puede inferir que cada autor hace explícita una preferencia, declara un estilo personal en su concepción de literatura, cualitativamente diferente de un autor a otro. Lo más importante, sin embargo, consiste en las inferencias obtenidas a partir de la frecuencia o concentración de actividades, de la variedad y orientación de estas, e incluso de las ausencias, i.e., las actividades omitidas.

$\mathrm{Si}$ se quiere caracterizar cada uno de los manuales por su estilo de enseñanza con base en su enfoque o acercamiento metodológico y sobre todo por el énfasis que dedica a ciertas actividades escolares, encontramos lo siguiente: 
Literatura Universal de David Fernández es el del método que enfatiza la lectura de obras completas. En cuanto a actividades, éstas se concentran, sin sobresalir demasiado, en "comentar" (30 y 23 casos = 53), "explicar" (31 y $21=52$ ), "identificar" (36), "señalar" (30 y 8 = 38), "preguntas generales" (38 y 62=100) y en "preguntas parciales" (179 y $236=415)$. Las segundas cifras reportadas entre paréntesis corresponden a sub-apartados de los mismos manuales. En el manual de Fernández corresponden a las actividades de trabajo de cuatro obras completas: Odisea de Homero, Romeo y Julieta de Shakespeare, Madame Bovary de Flaubert, y Metamorfosis de Kafka.

Literatura Universal de Gadea y Freixes es el manual que después de trabajar la literatura en la escuela, la lleva a las otras artes, a la sociedad y a la cultura; es el manual de la intertextualidad. Sus actividades aparecen en dos partes, las propias del análisis de los textos literarios y otras actividades, a las que denomina "per traballar" y se refieren a actividades extra-clase, o extra aula. Las más frecuentes son "comparar" (50 y $10=60)$, y "actividades relacionadas con la organización de eventos extra-aula, tales como debates y audiciones" (25 y 2 = 27).

Literatura Castellana de José Quiñonero es el manual que se concentra en las actividades creativas y la imaginación. Se centran ellas en "componer o redactar composiciones creativas" (17 casos, actividad no incluida en el concentrado), "imaginar "(8), "analizar" (38 y 1), "comentar" (72 y 1) y "explicar" (62).

Literatura española 2 de Carreter y Tusón se caracteriza por la variedad en la selección de textos, no solamente castellanos sino también hispanoamericanos, además de los de variedad lingüística peninsular. En cuanto a actividades, sobresalen, "comentar" (30 casos), "señalar" (46), "observar" (62), "preguntas generales" (91) y "preguntas parciales" (277).

Los cuatro manuales presentan en común las actividades: "comentar, comparar, explicar, señalar, observar". "Analizar "y" valorar" son comunes a tres. Es decir, en pocas palabras, la literatura se reduce, en el mejor de los casos, a comentario, explicación, análisis, identificación o señalamiento, y con menor frecuencia a comparación y evaluación. Estas actividades, sin embargo, escasa o ninguna caracterización específica hacen de la literatura. En todo caso los 
ejercicios remiten a actividades que igualmente se pueden hacer con textos no literarios, como el ensayo, el reportaje, el artículo periodístico, la noticia, la reseña. $\mathrm{Y}$, la particularidad literaria difícilmente alcanza a vislumbrarse. La literatura no se enseña como lenguaje ambiguo, inestable, constituido de diversos niveles semánticos y por lo tanto susceptible de variadas significaciones. Simplemente los cursos de literatura están dirigidos a enseñar a leer textos mono-significativos, monovalentes.

La vista en perspectiva de la distribución de tareas y ejercicios, nos permite ver el énfasis en ciertas actividades o en objetivos de aprendizaje, los cuales, a criterio de los autores de los manuales, encausan la adquisición de la formación literaria. También, sin embargo, debido a un frecuente sobre énfasis de ciertas actividades resaltan huecos o ausencias importantes. Corcoran y Evans sostienen que la actividad mental de cualquier lector independientemente de su nivel escolar, engloba cuatro niveles que, contrariamente a lo que podríamos esperar, no son reflejadas en los manuales de una manera equitativa y sistemática. Tales niveles son: 1) figuración e imaginación, 2) previsión y retrospección, 3) participación y construcción y 4) valoración y evaluación. Si se atiende a lo señalado por Corcoran y Evans, los manuales no se han propuesto las actividades ni proporcionada ni ponderadamente. Sólo el manual de Gadea y Freixes equilibra cada una de las cuatro áreas, pero los demás, cuando se orientan a la valoración y a la figuración e imaginación, lo hacen de una manera apenas aproximada. Desde un punto de vista conservador, las actividades se dirigen generalmente a la previsión y retrospección, como cuando el lector avanza hipótesis sobre el desarrollo de la narración o reflexiona sobre preguntas o simplemente considera lo que debe ser aprendido y de lo que debe tomar conciencia para evaluar una lectura. También la participación y la construcción del significado se ven estimuladas en función de algunas actividades casi siempre presentes y utilizadas en alta frecuencia: comentar, observar, explicar, analizar, describir, exponer, etc.

Insistimos en que un dato significativo es la presencia en unos y la ausencia total, o casi total en otros, del recurso a diversas estrategias para sus actividades. Entre ellas se puede observar el recurso a las preguntas de carácter general y parcial para comprobar que 
los alumnos comprenden el texto literario. (Las preguntas generales pueden contestarse con un sí o un no; las parciales solicitan información específica y se construyen con un pronombre del tipo: dónde, cómo, cuándo, quién, etc.). El recurso a las preguntas como es utilizado en tres manuales (ausente en el manual de Quiñonero), tiene por limitación fomentar casi siempre únicamente la reacción intelectual del estudiante. Además, si se las usa como actividad preponderante se tiende a orientar, a dirigir, incluso dijéramos a manipular, la atención de los estudiantes. El caso pareciera aún más serio en las preguntas de carácter total del tipo: ¿Has observado que...? ¿No te has dado cuenta que...? En éstas el objetivo desemboca en un intento por enseñar como conocimiento, la apreciación, la interpretación, la evaluación que indica el manual. No se hace participar al alumno en la comprensión, en la construcción del significado, en la interpretación de la lectura, en los sentimientos que puede provocar la recepción en el lector. Están ausentes la gradación apreciativa, el acercamiento paulatino a la aceptación, la negociación entre partes, en síntesis, la enseñanza estratégica del arte.

\section{Conclusiones}

En las conclusiones expuestas en seguida es necesario precisar que se trata de generalizaciones atrevidas en las que casi siempre hay una excepción a la regla. Tres manuales sí cumplen con un punto y otro manual, no. Tres manuales manifiestan una preferencia o visión y, en cambio, otro no la trabaja. De modo que por el momento, dado que se maneja una muestra reducida, la conclusiones solo pueden quedar reducidas a estos manuales.

1. El concepto de literatura manejado por los autores de los manuales analizados, queda reducido, con muy escaso porcentaje en su dirección contraria, al concepto conservador de literatura del canon, la denominada literatura de la alta cultura, la literatura sancionada por la tradición.

2. En los manuales se alude a la literatura como un concepto terminado, cerrado, incuestionable en valor literario y cultural. Por lo tanto, los ejercicios y actividades de clase son propiamente de exégesis o apologías, pues, una vez cosificadas y feti- 
chizadas, las obras no pueden ser motivo de crítica ni de cuestionamiento iconoclastas.

3. En el manejo de actividades no se apela a la explicitación de sentimientos, la infinita gama de emociones que experiencia el lector. La mayoría de las actividades, si no todas, apelan al nivel intelectual, cognoscitivo, concretizadas en el análisis y la síntesis.

4. No existe un intento decidido por llevar a la literatura más allá de la comprensión intelectual, en dirección a la recepción estética. Escasamente las actividades fomentan la imaginación, la invención, el carácter lúdico, la literatura como fuente de placer estético.

5. Continúa concibiéndose la literatura como actividad y producto propio de hombres; es muy escasa la presencia de muestras de literatura escrita por mujeres. Lo grave y negativo de esta orientación es presentarla a los alumnos como natural.

6. La enseñanza de la literatura está dirigida a la adquisición de habilidades de comprensión, pero ocultando o, mejor dicho, olvidando lo sui géneris del discurso literario: la ambigüedad, la inestabilidad de su significado, la subversión ideológica o su faceta política. Dicho de otro modo, el objetivo de los manuales es el de enseñar a leer un texto, a acceder a un sentido, pero no a interpretarlo; no se ofrece orientación para ver otro significado detrás de un primer significado.

7. Continúa creyéndose que la literatura constituye un sistema cerrado, sin conexión con otros sistemas: ni con otras disciplinas -las humanidades-, ni con otras artes -la pintura, la música, el cine, el teatro, la cultura, la filosofía, la historia, la psicología.

8. Finalmente, para enfatizar repitiendo, a partir de las prácticas escolares propuestas por los manuales mencionados, se infiere que a la literatura se le otorga una función meramente pragmática, es apenas un instrumento, un apoyo para la enseñanza de la lectura en general sin atender la especificidad del lenguaje literario. 


\section{Bibliografía}

Ballester, Joseph. "Teorías literarias y su aplicación didáctica." Mendoza, Conceptos 297-322.

Bertochi, Daniela. "La aproximación lingüística y literaria en el bachillerato: innovación y retos ante el cambio." Textos de didáctica de la lengua y la literatura 15 (1995): 15-27.

Bordons, Glòria y Anna Díaz-Plaja. Literatura comparada (catalana i castellana). Propostes de treball. Barcelona: Empúries, 1993.

Cantero, F. y Antonio Mendoza. "Conceptos básicos en Didáctica de la lengua y la literatura." Didáctica de la lengua y la literatura. Coord. Antonio Mendoza Fillola. Madrid: Prentice Hall, 2003. 33-78.

Coll César y Javier Onrubia. "Discusión entre alumnos e influencia educativa del profesor." Textos de didáctica de la lengua y la literatura 20 (1999): 19-37.

Colomer, T. "La didáctica de la literatura: temas y líneas de investigación e innovación," Coord. Carlos Lomas, La educación lingüística y literaria en la enseñanza secundaria. Barcelona: ICE/Horsori, 1996. 123-142.

Corcoran, B. y E. Evans, eds. Readers, Texts, Teachers. Nueva Jersey: Boynton/Cook, 1987.

Culler, Jonathan. "Literary Theory in the Graduate Program." The Pursuit of Signs. Edición aumentada. Ithaca, Nueva York: Cornell UP, 2002. 210-226.

Fernández, David. Literatura Universal. Barcelona: Castellnou Edicions. 1999.

Fish, Stanley. "Is There a Text in This Class?" Is There a Text in This Class? The Authority of Interpretive Communities. Cambridge, Massachusetts/ Londres, Inglaterra: Harvard University, 1980. 303-21.

Gadea Ferrán y Andreu Freixes. Literatura Universal. Barcelona: Teide, 2002.

Garrido, Miguel Angel. "Didáctica de la literatura," Nueva Introducción a la teoría literaria. Madrid: Síntesis, 2001. 317-347.

Graff, Gerald. "How to Deal with the Humanities Crisis: Organize it." ADE [Association of Departments of English]. Bulletin 95. Primavera 1990: 4-10. 
Holland, Norman N. 5 Readers Reading. New Haven y Londres: Yale UP, 1975.

Iglesias Santos, Montserrat. "El sistema literario: teoría empírica y teoría de los polisistemas." Avances en teoría de la literatura. Comp. Darío Villanueva. Santiago de Compostela: Universidad de Santiago de Compostela, 1994.

Lázaro Carrreter, Fernando, ed. Literatura y Educación. Madrid: Grupo Anaya, 1974.

Lázaro Carreter, Fernando y Vicente Tusón. Literatura Española 2. Madrid: Grupo Anaya, 1995.

Mendoza Fillola, Antonio, coord. Conceptos clave en didáctica de la lengua y la literatura. Barcelona: Horsori/Universidad de Barcelona, 1998.

Moukarovsky, Jan. "Función estética, norma y valor estético como hechos sociales." Escritos de estética y semiótica del arte. Edición crítica de Jordi Llovet. Barcelona: Editorial Gustavo Gili, 1975. 44121.

Orozco, Ana. "La literatura en el bachillerato." Textos de didáctica de la lengua y la literatura 15 (1998): 61-69.

Quiñonero, José. Literatura Castellana. Barcelona: Ediciones Octaedro. 2001.

Segre, Cesare. Principios de análisis del texto literario. Barcelona: Crítica, 1985.

Schmidt, Sigfried, J. Fundamentos de la ciencia empirica de la literatura. Versión castellana de Francisco Chico Rico. Madrid: Taurus, 1990. 